\title{
Perceived Professional Characteristics as Correlates of Success Potential Among the Catholic Priests in Selected Dioceses in South-West Nigeria
}

\author{
Chigozie Okenwa ${ }^{1 *} \quad$ Afusat Busari ${ }^{2}$ \\ 1.Schoenstatt Fathers Community, Ijokodo, Ibadan \\ 2.Department of Guidance and Counselling, University of Ibadan, Ibadan, Nigeria
}

\begin{abstract}
The modern day priesthood is not just about preaching or meeting the spiritual need, but also the ability to competently attend to the physical and psychological needs of the congregants. A priest is expected to discharge assigned duties in such a way that optimum success is achieved. However, while priest are being theologically prepared, there is the need to also examine some of the psychological traits that could help priests to be successful in the work of the gospel. Hence, this study examined perceived professional characteristics as correlates of success potential of Catholic Priests in selected Dioceses in Southwest Nigeria. The professional characteristics used in the study are genuineness, unconditional positive regard, empathic understanding and reflective listening. The study adopted the descriptive research design of correlational type. Simple random sampling was used to select three Catholic dioceses in the Southwest of Nigeria while, all population sampling technique was used to select 203 priests that formed the respondents of this study. Questionnaire was used to collect data for the study which include Success Potential Scale $(\alpha=0.85)$, Empathy Scale $(\alpha=0.79)$, Reflective Listening Scale $(\alpha=0.89)$ and Unconditional Positive Regard Scale $(\alpha=0.81)$. Pearson Product Moment Correlation (PPMC) and Multiple Linear Regression were used for data analysis at 0.05 level of significance. The result of the study shows that genuineness $(\mathrm{r}=.503, \mathrm{p}<0.01)$, unconditional positive regard $(\mathrm{r}=.776, \mathrm{p}<0.01)$, empathic understanding $(\mathrm{r}=.746$, $\mathrm{p}<0.01)$ and reflective listening $(\mathrm{r}=.746, \mathrm{p}<0.01)$ had positive relationship with success potential of the priests. The independent variables had significant joint contribution of $65.4 \%$ to success potential of the respondents. In addition, reflective listening $(\beta=0.427, \mathrm{t}=4.919, p<.01)$, unconditional positive regard $(\beta=0.264, \mathrm{t}=2.521, p<.05)$, empathic understanding $(\beta=0.155, \mathrm{t}=2.431, p<.05)$ and genuineness $(\beta=0.112, \mathrm{t}=2.188, p<.05)$ had significant relative contribution to success potential of the Priests. Based on this study, it was concluded that genuineness, unconditional positive regard, empathic understanding and reflective listening are professional characteristics that correlate with success potential of Catholic Priests in Selected Dioceses in Southwest Nigeria.
\end{abstract}

Keywords: Success potential, professional characteristics, genuineness, unconditional positive regard

DOI: $10.7176 / \mathrm{DCS} / 10-3-04$

Publication date:March $31^{\text {st }} 2020$

\section{Introduction}

In this modern time, a priest is one who not only provides the spiritual assistance, but also ensures necessary priestly services are provided in order to make parishioners or laities become a well-balanced individuals. Today's Catholic priest plays a number of roles, part of which is to provide pastoral counseling services to parishioners and members of the public, as the need may arise. Within this context, the Catholic priest must employ his knowledge of theology, the Bible and spirituality to help individuals overcome such problems as depression, anxiety, marriage and family conflicts, and drug and alcohol abuse (Worthington, Kurusu, McCollough and Sandage, 1996). According to Woodruff (2002), priests spend several hours annually with individuals in pastoral counseling, a form of therapy that combines both secular therapeutic techniques and spirituality. Just like in secular setting, a priest wants to be successful in the assigned pastoral duties by helping to meet both the physical and spiritual needs of the congregants. Therefore, one of the areas of concern in theological training is to determine and improve the success potentials of the priests once they get to the pastoral field, which is the parish or church.

The word "success" comes from a Latin word "successus" which means "a happy outcome." The verb form is "succedere" which means "to succeed" or "to accomplish a desired end." Success could also connote the accomplishment or achievement of an aim or purpose. In a nutshell, success connotes achieving a set targets, goals and ambitions as and when due, without wastage of human or capital resources. Hence, success as a psychological construct is a relational term that measures performance or achievements in terms of input and output, expectations and results, needs and actualization, intention and action, resolution and action, value and attitudes, etc.

Animashaun (2012) defined success as achievement of intentions, attainment of fame, wealth or power, when an undertaking turns out as planned or as intended, the result of commitments, toughness, endurance, persistence, effective management of pressing demands made on the individual, having money all the time, knowing what you know how to do best and finding people to pay for it, an evident improvement or progress, getting up just one 
more time than you fell, a good result that removes insult, being at the desired place at the right time and doing the right thing at the right time, doing something highly rewarding to oneself and beneficial to mankind in general, influencing other people's lives positively, continuous achievement of worthwhile goals, hitting a jackpot or luck, feeling satisfied and fulfilled at the end of one's life time, being happy throughout one's life with just enough money to cater for one's needs, setting out to do something and being able to initiate action steps in realizing such set goals.

Furthermore, Akinboye (2003) expressed that the components of success are intelligent Quotient (IQ), emotional intelligence (EQ), creativity (CR) and innovation (IN). Based on Akinboye's (2003) exposition, success is a total summation of these four components, which could be mathematically represented (i.e., $I Q+E Q+C R+I N$ = success). Emmanual (2003) submitted that natural laws guide success such as the laws of self-discovery, focus, self-development, diligent and thoroughness, consistency, persistence, mentorship, prudence/frugality, planning, customer/client satisfaction, kingdom investment, divine timing and the law of grace. In addition, Oyedepo (2006), conceptualized success as an all-encompassing construct, involving many components out of which vision, information and hard-work stand out as the major ones from such other components which he called "systems" which are foundation, imagination, purpose, task, mental, race, choice, financial, fortune, premarital, marital and covenant success habits. Animasahun (2007), submitted the following components of success potential: positive self-components, decision-making, goal-setting, hard-work, creativity and innovation, emotional intelligence, entrepreneurship behaviour, character development, perseverance, faith in God, time management, self-control, leadership development, problem handling and overcoming disadvantaged complex.

Notably, having success potentials by priests is not a natural inheritance, but a product of psycho-sociological factors. As professionals, achieving pastoral success demands possession of necessary qualities in addition to the theological training. These qualities could be regarded as professional characteristics that a priest may possess in achieving success, especially in the area of remedial and rehabilitation services. Hence, this study will be anchored on the professional qualities as espoused by Carl Roger. These professional characteristics are: genuineness, empathetic understanding, unconditional positive regard and reflective listening. Genuineness is one of the professional characteristics that are of interest in this study. It is perceived to be very essential to the success of a priest because priests are expected to be integrated or similar to their ideal-self.

Genuineness and authenticity have often being used interchangeably (Gelso and Carter, 1994 as cited by Schnellbacher and Leijssen, 2009). Schnellbacher and Leijssen, (2009) defined genuineness, as the ability and willingness to be what one truly is toward oneself and the other in mutual relationship. For Schnellbacher and Leijssen (2009) therefore, self-awareness is at the root of genuineness. Lambert (1992) submitted that practically all therapeutic orientations consider therapist genuineness as important for significant progress in psychotherapy, and, in fact, fundamental in the formation of a working alliance. According to Wyatt, (2001), genuineness has multiple conceptual elements in the form of different strongly intertwined processes.

Based on an extensive literature study, Schnellbacher and Leijssen (2009) defined genuineness in psychotherapy as a function of self-awareness, self-presence and self-disclosure. Furthermore, genuineness is about being aware of one's own experience (self-awareness); being emotionally involved in the client's story and the here-and-now interaction, being personally present (self-presence); and being willing to intentionally and verbally reveal personal feelings, thoughts, impressions, experiences, facts, views, values, and methods of working. Hence, therapist genuineness is an inner attitude, a relational experience, and a dynamic process between client and therapist.

Several studies have demonstrated a positive correlation between therapist congruence and positive outcome in therapy (Kolden, Klein, Wang, and Austin, 2011). Kolden, Klein, Wang, and Austin (2011) conducted a metaanalysis on research studies conducted to explore the relationship between therapist congruence or genuineness and client outcome. The authors reported estimates of effect sizes ranging from -.26 to .69 and an overall aggregate effect size of .24 for congruence. The authors interpreted this as a small to medium effect for congruence and concluded that congruence was an important dimension of the therapeutic relationship. Although Kolden et al. recognized the limitations of inconsistent methodology in the original studies, the small number of studies included, researcher bias, and restricting access to unpublished studies, they concluded that there is a positive relationship between therapist congruence and psychotherapy outcome. The authors encouraged further exploration of congruence in person-centered therapy and provided several recommendations for fostering congruence in therapeutic practice.

Empathetic understanding is another professional characteristic that will be considered in this study. Empathetic understanding means understanding things from the internal frame of reference, rather than external or objective frame of reference (Patterson and Joseph, 2007). Counseling psychologists agree on the importance of empathy in counseling relationship but have divergent views on how it could be expressed. Empathy should not mean incongruent or unprofessional identification with the client. Meanwhile, it is difficult to draw the line between what could be termed professional and unprofessional empathic understanding. Empathy according to Rogers is an accurate empathetic understanding of the client's world as seen from the inside. It means, to sense the 
client's private world as if it were your own, without losing the "as if quality" (Rogers (1961). Hence, Rogers was aware of the difficulty in achieving maximum empathic understanding. According to him, the difficulty stems from the fact that empathetic understanding is about understanding another person from his internal frame of reference. An empathetic way of observing others cognitively or objectively, is rather, to obtain facts about their perceptions, ideas, attitudes, feelings, emotions while at the same time correlating them empathically with our own behaviour, feelings, sensation, interaction and cognition.

Affective empathy, or emotive empathy, is viewed as identifying with the emotional expression or experience of another person, in the sense that the counselor feels what the client feels or draws on previous personal experiences to connect with the emotional content of the client (Kohut, 2010; Stepien and Baernstein, 2006; Tudor, 2011). A second definition, moral empathy, refers to a motivation to connect with and understand another's reality (Stepien and Baernstein, 2006; Zaki, 2014). This definition suggests that a person must intentionally choose to act in an empathic way for it to be fully expressed, and thus empathic connection cannot be accidental in its application. Cognitive empathy, in turn, involves the counselor's ability to accurately understand client statements from a more distanced and objective perspective (Stepien and Baernstein, 2006). Behavioral empathy is the application of verbal and nonverbal responses that convey understanding to a client. Unconditional positive regard is another perceived professional characteristic that is of interest to this study. Positive regard is seen from two sides which are conditional positive regard and unconditional. In Roger's stance conditional positive regard is also psychologically, a bad treatment that can make us to disparage ourselves as well as others. People who were affected by conditional positive regard or possessive love are so much affected by the mistakes of others thereby becoming incongruent or dissimilar with their real-selves. Overall, this conditional positive regard is not sufficient to bring about therapeutic success; hence, Roger instructed that this should be jettisoned.

Pantalon, Chawarski, Falcioni, Pakes, and Schottenfeld (2004) measured therapist empathy during community reinforcement approach treatment sessions for pregnant and postpartum cocaine users. They used a behavioral rating system (Mechanisms of Action Rating Scale: MARS) to capture frequency counts for the occurrence of therapist empathy and responses to resistance during videotape reviews of sessions. Successful client outcome was defined as urine-verified, continuous abstinence from cocaine for three consecutive weeks during treatment. The authors found that therapists with higher rates of empathy had clients with significantly lower rates of cocaine use. Similarly, there was a significant relationship between more positive therapist skills in managing resistance and improved cocaine abstinence for these women.

According to Rogers, unconditional positive regard works, as part of the therapeutic relationship, by diminishing conditions of worth which are at the root of the incongruence between organismic experience and the self. As conditions of worth are acquired through a conditionally valuing relationship, unconditional positive regard is seen to stimulate the exact opposite, a climate of unconditional acceptance and warmth. It is the very unconditionality of this climate that promotes growth, for it enables the processes of psychological defense to be reversed. This reversal is simply a product of the degree of threat presented by conditions of worth being gradually eroded by the presence of an unconditionally warm and accepting other (Rogers, 1959). The role of unconditional positive regard is enmeshed with the processes of empathy. In contacting denied or distorted organismic experiencing that is then unconditionally accepted and valued by a therapist who is empathically attuned, the client is able to feel fully accepted and thus develop a greater sense of positive self-regard.

Farber and Doolin (2011) provided a review of research on positive regard and conducted a meta-analysis of research on the correlation between counselor's provision of positive regard and therapeutic outcome. The authors included 18 studies that evaluated the relationship between positive regard and therapeutic outcome and reported an aggregate effect size of .27 and concluded that positive regard has a moderate association with therapy outcomes. The authors considered the small number of studies included in the meta-analysis to be a limitation of the study and noted that their stringent inclusion criteria and the decrease in research on positive regard within the last 20 years as factors that influenced the sample size. The authors concluded that the therapist's ability to provide positive regard is significantly associated with therapeutic success, but interpreted the moderate effect size as indicative of the reality that many other relational factors influence therapy outcomes. Farber and Doolin made several recommendations for clinical practice including the continued provision of positive regard, kindness, and warmth towards clients across theoretical approaches and therapist self-awareness of their provision and communication of unconditional positive regard to clients and therapist awareness of the unique needs of individual clients for unconditional positive regard. Farber and Doolin (2011) found a positive relationship between unconditional positive regard and therapeutic outcome in their meta-analytic review.

Furthermore, reflective listening is one of the perceived professional characteristics that would be considered in this study as predictor of success potential of catholic priests. According to Gordon (1970) cited by Rautalinko (2004), reflective listening (RL) occurs when someone in a conversation tries to understand what it is the sender's feeling is or what the message means. In counselling process, the therapist should be able to put self-understanding into words and feed it back for the sender's verification. Lindh and Lisper, (1990) defined reflective listening as when therapist paraphrases words that another person has said, including both his factual and emotional 
information, and adding nothing.

Professionally, reflective listening implies that the therapist should possess the capability to ensure that the content of the client's story is not altered but correctly interpreted. According to Rautalinko (2004), the therapist does not send a message that suggests evaluation, opinion, advice and logic. The purpose of reflective listening is to encourage someone to talk by verifying the message in a non-judgemental fashion and in this way it is nondirective. The therapist must not be judgmental, but could ask leading questions for clarification. This step will make a client to see therapist as a partner and friend, who is willing to render help that could help overcome the pressing challenges.

Segre, Stasik, O'Hara and Arndt, (2010) conducted a study where women with depressive symptoms received up to six therapeutic listening visits at home. The variables investigated were: depression, life satisfaction and acceptability of treatment. Participants were interviewed at three different moments: pre-visit ( 0 months), postvisit (2 months after the visits) and follow-up (five months after of the visits had started or three months after the last visit). According to the results, during the five months between the pre and post-visit, the mean scores of all measures of depression decreased $(p<0.0001 ; p=0.03 ; p=0.004)$. 63.2\% of women were considered recovered and two thirds showed clinically significant improvement. Regarding life satisfaction, the results indicated positive change in this variable over time $(\mathrm{p}=0.01)$. The average of the instrument used to measure the acceptability of treatment was 5.7, indicating that women considered the Therapeutic Listening Visits as very useful.

According to Akinade (2012), counselling is a process of helping an individual become fully aware of oneself and the ways in which he is responding to the influences of one's environment. It further assists to establish some personal meaning for this behaviour and to develop and classify a set of goals and values for future behaviour. According to Oviogbodu (2015) counselling can be defined as a number of procedures in assisting an individual to solve his problems. Counselling is more involved emotionally in the affective realm, on personalized learning, that is, emotions and feelings, values, attitudes. Counselling is an interaction or relationship between two or few individuals, the client-counsellor relationship of trust (Geshinde 1991; Adebowale, 2012; cited in Oviogbodu, 2015).

Moreover, counselling is a learning process in which a counsellor helps an individual or individuals learn, understand themselves and their environment and be in a position to choose the right type of behaviours that will help them develop, grow, progress, ascend, mature and step up, educationally, vocationally and socio personally (Egbo, 2013). Counselling is a person-to-person process in which one person is helped by another to develop, increase in understanding and ability to solve his or her problems (Ebizie, Enajedu and Nkechi, 2016). Professional counselling is a safe and confidential collaboration between qualified counsellors and clients to promote mental health and wellbeing, enhance self-understanding, and resolve identified concerns. Clients are active participants in the counselling process at every stage (Psychotherapy and Counselling Federation of Australia, (PACFA, 2018).

Lai- Yeung, 2014 seems to suggest that the main bulk of remedial and reformatory is central in counselling services which has to do more with supportive and remedial work. Furthermore, the global trend seems to have moved from a casework and remedial approach to a preventive, developmental approach in providing guidance and counselling (Lai-Yeung, 2014). Within the remedial and reformatory framework, while other mental health professionals approach mental health using a medical model, counselling uses a non-medical, biopsychosocial model (Stallman, 2018). Counselling focuses on the treatment and prevention of mental illness, while actively promoting mental health and wellbeing. The focus on client well-being is seen as a distinguishing feature of counselling (O'Hara and O'Hara, 2015). According to PACFA (2018), counselling within the remedial and reformatory spectrum could help client explore and address issues that are related to aspects of identity, spirituality, relationships with self and others, past experiences, parenting, grief and loss, trauma, domestic violence, child abuse, use of alcohol and other substances, depression, anxiety, and other mental health concerns.

Moreover, the scope of remedial and reformatory counselling has to do with correcting maladaptive behaviours, anti-social behaviour, self-defeating behaviour and counter-productive behaviour. For instance, sexual risk behaviours, addiction, destructive tendencies, etc. are some of the behaviours that could be exhibited by church members which could inform the need for remedial and reformatory counselling. Furthermore, remedial and reformatory counselling could help church members who might have had prison experience before; and this will help further re-integration and avoidance of recidivism. In addition, the scope of remedial and reformatory counselling could cover the symptoms of mild anxiety and depressive disorders which include hopelessness, sadness, sleep disturbances, motivational impairment, relationship difficulties, and suicide in the most severe cases (American Psychiatric Association, 2013).

A church is always consisting of people of diverse nature, needs, challenges and behaviours. The needs of church members could range from physical to spiritual needs, which demand the spiritual and professional assistance of the Priest in charge of the parish. Besides, there are many members that are seen as demonstrating maladaptive and anti-social behaviour, as well as those that are just recuperating from problematic conditions. This set of people need some level of remedial and reformatory program in order to develop adaptive behaviour that will ensure usefulness to self and the society. Meanwhile, examining the factors that could associate with the 
success potential of Catholic Priest will help bring about more success and professionalism into the priestly ministry.

Most significantly, since studies are yet to focus on examination of the presence of these professional characteristics and how each characteristic could correlate with the success potential of Catholic priests especially those that offer remedial and reformatory program, this study examined perceived professional characteristics as correlates of success potential of Catholic Priests in Selected Dioceses in the Southwest of Nigeria.

\section{Purpose of the Study}

The main purpose of this study is to investigate perceived professional characteristics as correlates of success potential of Catholic Priests in Selected Dioceses in Southwest of Nigeria. Other purposes of the study are to:

- determine the significant correlation among perceived professional characteristics (genuineness, unconditional positive regard, empathic understanding and reflective listening) to success potential of Catholic Priests in Selected Dioceses in the Southwest of Nigeria.

- $\quad$ examine the joint contribution among perceived professional characteristics (genuineness, unconditional positive regard, empathic understanding and reflective listening) to success potential of Catholic Priests in Selected Dioceses in the Southwest of Nigeria.

- Investigate the relative contribution among perceived professional characteristics (genuineness, unconditional positive regard, empathic understanding and reflective listening) to success potential of Catholic Priests in Selected Dioceses in the Southwest of Nigeria.

\section{Research Questions}

The following research questions were raised and answered in this study:

i. Is there any significant correlation among perceived professional characteristics (genuineness, unconditional positive regard, empathic understanding and reflective listening) to success potential of Catholic Priests in selected Dioceses in the Southwest of Nigeria?

ii. What is the joint contribution of perceived professional characteristics (genuineness, unconditional positive regard, empathic understanding and reflective listening) to success potential of Catholic Priests in selected Dioceses in the Southwest of Nigeria?

iii. What is the relative contribution of perceived professional characteristics (genuineness, unconditional positive regard, empathic understanding and reflective listening) to success potential of Catholic Priests in selected Dioceses in the Southwest of Nigeria?

\section{Methods \\ Design}

The study adopted the descriptive research design survey of correlational type. This design is based on the fact that the research method scrutinizes the accuracy of phenomenon under study as they are resident in the respondents and provides precise description of the responses of the respondents without manipulating the variables. This design is used when the research does not involve manipulation of any of the study variables.

\section{Population for the study}

The population of this study comprises Catholic priests (both Diocesan and religious) working in selected Catholic Dioceses located in the southwest of Nigeria, namely Ibadan, Abeokuta and Oshogbo.

\section{Sample and sampling techniques}

The sample of this study comprised 203 priests in selected Dioceses in southwest of Nigeria, namely, Ibadan Archdiocese, Oshogbo Diocese and Abeokuta Diocese. The researcher employed simple random sampling to select three Catholic Dioceses in the Southwestern Nigeria while all population sampling techniques was use to select 203 priests. Of all the two hundred and three (203) priests that responded to the questionnaire, 88 respondents (43.4\%) were selected from Ibadan Archdiocese, 64 respondents (31.5\%) were from Oshogbo diocese and 51 respondents (25.1\%) were selected from Abeokuta diocese. 108 priests $(53.2 \%)$ were from Diocesan priests, while $95(46.8 \%)$ were from Religious priests. In addition, 41 of the respondents $(20.2 \%)$ were between the ages of 20 to 30years; 68 respondents $(33.5 \%)$ were between the ages of $31-40,79$ of the respondents $(38.9 \%)$ were between the ages of $41-50$ years and 15 of the respondents $(7.4 \%)$ were between the ages of 51 years and above. 31 $(15.3 \%)$ respondents were ordained between 1980 and 1990; 52 (25.6\%) were ordained between 1991 and 2000; 62 respondents $(30.5 \%)$ were ordained between 2001 and 2010 ; while 58 respondents $(28.6 \%)$ were ordained in year 2011 and beyond.

\section{Instrumentation}

The research instrument employed to gather responses from the respondents was questionnaire. The questionnaire 
was arranged in six sections (A to F). Section "A" which comprised of the demographic data such as: age, nationality, diocesan or religious priest, and year of ordination. Section "B" to F contains scales on all the variables examined in the study. The details of these scales are provided below.

Section B: Success Potential Scale (SPS)

Success Potential Scale was adapted from Success potential battery developed by Animasahun (2013). The researcher adapted 45 items that could measure success potential of priests from different components developed by the author. Using four Likert format, each of the 45 items on this section has it responses ranging from Strongly Agree $=5$ to Strongly Disagree $=1$. Some samples of the items read: "success is knowing what you know how to do best and finding people to pay you for it"; "success is doing something highly rewarding to oneself and beneficial to mankind in general". Using split-haft method, the internal consistency of the scale yielded a Cronbach $\alpha=0.79$ after pilot study administered to 20 priests in Ondo Diocese who were not part the study.

Section C: Empathy Scale (EC)

Empathy Scale was adapted from Toronto Empathy Questionnaire (2001). It consists of fifteen (15) items that measures empathy of the priests. The range of responses is from Never $=0$, Rarely $=1$, Sometimes $=2$, Often $=3$, Always $=4$. Consequently, the negatively worded items are reversed. Some samples of the positively worded items are: "when someone else is excited, I tend to get excited"; "it upsets me to see someone being treated disrespectfully". Through the use of split half method, the internal consistency of the scale following the pilot testing is Cronbach's $\alpha=0.85$.

\section{Section D: Genuineness scale (GS)}

Genuineness scale was adapted from Authenticity Scale developed by Wood, Linley, Maltby, Baliousis and Joseph, (2008). Specifically the items in this scale were designed to measure the genuineness of the participants in the study. This section consists of twenty five (25) items, using a four point Likert responses to each of the items in this section rang from Strongly Agree $=5$ to Strongly Disagree $=1$. Sample of the items on the scale are: "I dislike people who pretend to be what they are not"; "I have to hide the way I feel inside". After pilot testing of the scale, the result of reliability analysis shows that the scale has a Cronbach $\alpha=0.79$, which is a sign that the scale is reliable.

\section{Section E: Reflective Listening Scale}

Reflective Listening Scale was adapted from “Active Listening Attitude Scale" developed by Kourmousi, Amanaki, Tzavara and Koutras (2017). The scale was developed to, ensure active listening skills. It consists of 31 items that are scored on a four-likert format scale, with response alternative being $1=$ strongly disagree, $2=$ disagree, 3 = agree and $4=$ strongly agree. Some samples of the items are: "I do not talk with someone else unless I have something to talk about"; "I am actually talking longer than the other person even in spite of my intention to listen to him or her". After the pilot testing of the scale, the result shows that the scale has a Cronbach $\alpha=0.89$, which indicates that the scale is reliable.

\section{Section F: Unconditional Positive Regard Scale (UPRS)}

This scale was developed by the researcher to measure the unconditional positive regard of the priests in their engagement in remedial and reformatory programs of the Catholic mission. It contains 10 items that is measured on a four-likert format that ranges from strongly agree to strongly disagree. Some of the items in the scale include: "I hold all human opinion in high regards"; "Regardless of the presenting problem, every individual most be respected"; "I believe that positive regard must be given to every individual regardless of their mental state of being", etc. Following the pilot testing of the scale, it has a Cronbach $\alpha$ of 0.81 which makes this scale reliable for use in this study.

\section{Method of Data Analysis}

In analyzing the data collected from the respondents, the researcher employed the descriptive statistics of percentage to calculate the demographic information while Pearson Product Moment Correlation (PPMC) and Multiple Linear Regression was used to analyze the data collected at 0.05 level of significance.

\section{Results}

\section{Demographic Data of Respondents}

Table 1: Frequency Distribution of Respondents by Location

\begin{tabular}{|l|l|l|}
\hline Location & Frequency & Percentage \\
\hline Ibadan & 88 & $43.4 \%$ \\
\hline Oshogbo & 64 & $31.5 \%$ \\
\hline Abeokuta & 51 & $25.1 \%$ \\
\hline Total & $\mathbf{2 0 3}$ & $\mathbf{1 0 0 \%}$ \\
\hline
\end{tabular}

Source: Field Survey

Table 1 indicates that 88 respondents (43.4\%) were from Ibadan Archdiocese, 64 respondents (31.5\%) were from Oshogbo diocese and 51 respondents (25.1\%) were from Abeokuta Diocese. The implication of this is that 
majority of the respondents were from Ibadan Archdiocese

Table 2: Frequency Distribution of Respondents by Type of priests

\begin{tabular}{|l|l|l|}
\hline Type of priesthood & Frequency & Percentage \\
\hline Diocesan Priest & 108 & $53.2 \%$ \\
\hline Religious Priest & 95 & $46.8 \%$ \\
\hline Total & $\mathbf{2 0 3}$ & $\mathbf{1 0 0 \%}$ \\
\hline
\end{tabular}

Source: Field Survey

Table 2 indicates that 108 priests (53.2\%) were from Diocesan priests, while 95 (46.8\%) were from Religious priests.

Table 3: Frequency Distribution of Respondents by Age

\begin{tabular}{|l|l|l|}
\hline Age Years & Frequency & Percentage \\
\hline $20-30$ & 41 & $20.2 \%$ \\
\hline $31-40$ & 68 & $33.5 \%$ \\
\hline $41-50$ & 79 & $38.9 \%$ \\
\hline 51 and Above & 15 & $7.4 \%$ \\
\hline Total & $\mathbf{2 0 3}$ & $\mathbf{1 0 0 \%}$ \\
\hline
\end{tabular}

Source: Field Survey

Table 3 shows that, 41 of the respondents $(20.2 \%)$ were between the age of 20 and 30years; 68 respondents $(33.5 \%)$ were between the age of 31 and 40years; 79 respondents $(38.9 \%)$ are between the age of 41 and 50 years; 15 respondents $(7.4 \%)$ were between 50 years and beyond. The respondents with age range 41 to 50 years participated more in the study.

Table 4: Frequency Distribution of Respondents by Years of Ordination

\begin{tabular}{|l|l|l|}
\hline Years of Ordination & Frequency & Percentage \\
\hline $1980-1990$ & 31 & $15.3 \%$ \\
\hline $1991-2000$ & 52 & $25.6 \%$ \\
\hline $2001-2010$ & 62 & $30.5 \%$ \\
\hline 2011 and above & 58 & $28.6 \%$ \\
\hline Total & $\mathbf{2 0 3}$ & $\mathbf{1 0 0 \%}$ \\
\hline
\end{tabular}

Source: Field Survey

Table 4 shows that 31 respondents $(15.3 \%)$ were ordained between 1980 and $1990 ; 52(25.6 \%)$ were ordained between 1991 and 2000; 62 respondents (30.5\%) were ordained between 2001 and 2010; while 58 respondents (28.6\%) were ordained in year 2011 and beyond. The respondents ordained between 2011 and 2010 participated more in the study.

Research Question I: Is there any significant correlation among perceived professional characteristics (genuineness, unconditional positive regard, empathic understanding and reflective listening) to success potential of Catholic Priests in selected Dioceses in the South West Nigeria?

Table 5: Descriptive Statistics and Correlational Matrix of Relationship between Independent Variables and Success Potential

\begin{tabular}{|l|l|l|l|l|l|l|l|l|}
\hline Variable & N & Mean & SD & $\mathbf{1}$ & $\mathbf{2}$ & $\mathbf{3}$ & $\mathbf{4}$ & $\mathbf{5}$ \\
\hline Success Potential & 203 & 159.78 & 39.28 & 1 & & & & \\
\hline Empathy Understanding & 203 & 45.04 & 5.60 & $.524^{* *}$ & 1 & & & \\
\hline Genuineness & 203 & 51.86 & 3.54 & $.503^{* *}$ & $.537^{* *}$ & 1 & & \\
\hline Reflective Listening & 203 & 78.43 & 14.93 & $.746^{* *}$ & $.333^{* *}$ & $.406^{* *}$ & 1 & \\
\hline Unconditional Positive Regard & 203 & 29.46 & 4.88 & $.776^{* *}$ & $.629^{* *}$ & $.511^{* *}$ & $.840^{* *}$ & 1 \\
\hline
\end{tabular}

**. Correlation is significant at the 0.01 level (2-tailed).

Table 5 shows a correlational matrix of the relationship among the independent variables (genuineness, unconditional positive regard, empathic understanding and reflective listening) to success potential of Catholic Priests in selected Dioceses in the South West Nigeria. The result of the study shows that empathic understanding has positive relationship with success potential of the priests $(r=.746, p<0.01)$. Moreover, the result shows that genuineness $(\mathrm{r}=.503, \mathrm{p}<0.01)$ has significant positive relationship with success potential of the participants. Similarly, reflective listening $(\mathrm{r}=.746, \mathrm{p}<0.01)$ also has significant correlation with priests' success potential. Likewise, unconditional positive regard $(\mathrm{r}=.776, \mathrm{p}<0.01)$ also has significant correlation with priests' success potential. Therefore, there was a significant positive relationship between genuineness, unconditional positive regard, empathic understanding, reflective listening and success potential of Catholic Priests in selected Dioceses in the Southwest of Nigeria.

Research Question II: What is the joint contribution among perceived professional characteristics (genuineness, unconditional positive regard, empathic understanding and reflective listening) to success potential of Catholic Priests in selected Dioceses in the Southwest of Nigeria? 
Table 6: Multiple Regression Analysis Showing Joint Contribution of Independent Variables to Success Potential

Multiple $\mathrm{R}=.813$

Multiple $\mathrm{R}^{2}=.661$

Multiple $\mathrm{R}^{2}$ (Adjusted) $=.654$

Standard Error of Estimate $=23.09947$

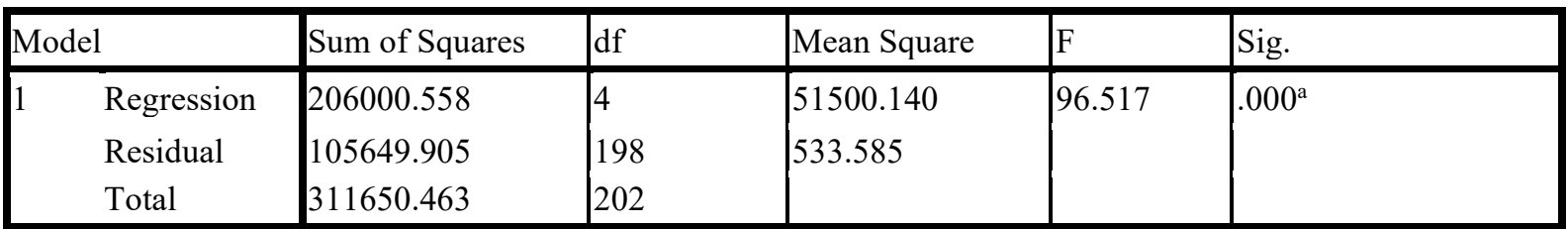

Predictors: (Constant), Unconditional Positive Regard, Genuineness, Empathic understanding, Reflective Li

b. Dependent Variable: Success Potential

From the table 4.6, the multiple regression table shows that $\mathrm{R} 2=.661$ and adjusted $\mathrm{R} 2=.654$. This implies that the independent variables jointly have contribution of $65.4 \%$ to success potential of the respondents. The result in the table shows f-calculated of 96.517 and f-significance of .000 . This means that the joint contribution of the independent variables to success potential was significant at 0.01 level of significance. Base on this result, it can be concluded that genuineness, unconditional positive regard, empathic understanding and reflective listening had significant joint contribution to success potential of Catholic Priests.

Research Question III: What is the relative contribution among perceived professional characteristics (genuineness, unconditional positive regard, empathic understanding and reflective listening) to success potential of Catholic Priests in selected Dioceses in the Southwest of Nigeria?

Table 4.7: Linear regression Showing Joint Contribution of Independent Variables to Success Potential

\begin{tabular}{|c|c|c|c|c|c|}
\hline \multirow[b]{2}{*}{ Model } & \multicolumn{2}{|c|}{ Unstandardized Coefficients } & \multirow{2}{*}{\begin{tabular}{|l} 
Standardized \\
Coefficients \\
Beta \\
\end{tabular}} & \multirow[b]{2}{*}{$\mathrm{T}$} & \multirow[b]{2}{*}{ Sig. } \\
\hline & B & Std. Error & & & \\
\hline $1 \quad$ (Constant) & -104.281 & 24.291 & & -4.293 & .000 \\
\hline Empathic Understanding & 1.090 & .448 & .155 & 2.431 & .016 \\
\hline Genuineness & 1.244 & .569 & .112 & 2.188 & .030 \\
\hline Reflective Listening & 1.122 & .228 & .427 & 4.919 & .000 \\
\hline Unconditional Positive Regard & 2.120 & .841 & .264 & 2.521 & .013 \\
\hline
\end{tabular}

Dependent Variable: Success Potential

Table 7 shows the relative contribution of each independent variable to success potential. The result shows that all the independent variables had relative contribution to success potential of Catholic priests. The most potent contributing variable to success potential was reflective listening $(\beta=0.427, \mathrm{t}=4.919, p<.01)$, followed by unconditional positive regard $(\beta=0.264, \mathrm{t}=2.521, p<.05)$. In addition, the third rank contributing variable was empathic understanding $(\beta=0.155, \mathrm{t}=2.431, p<.05)$ which was followed by genuineness $(\beta=0.112, \mathrm{t}=2.188$, $p<.05)$. Therefore, the result shows that genuineness, unconditional positive regard, empathic understanding and reflective listening) had relative contribution to success potential of Catholic Priests in selected Dioceses in the Southwest of Nigeria.

\section{Discussion of Findings}

The first research question sought to investigate if there is significant correlation among perceived professional characteristics (genuineness, unconditional positive regard, empathic understanding and reflective listening) to success potential of Catholic Priests in selected Dioceses in the Southwest of Nigeria. Based on the result of the study, there was significant positive relationship between genuineness, unconditional positive regard, empathic understanding, reflective listening and success potential of Catholic Priests in the Southwest of Nigeria. The result of this study corroborates various scholarly studies that have been conducted in related area. For instance, several studies (Kirschenbaum and Jourdan, 2005; Kolden, Klein, Wang, and Austin, 2011) have demonstrated a positive correlation between therapist congruence and positive outcome in therapy. The reason for this relationship has been espoused by Schnellbacher and Leijssen (2009) where it was emphasized that self-awareness is at the root of genuineness. Similarly, Lambert (1992) submitted that practically all therapeutic orientations consider therapist genuineness as important for significant progress in psychotherapy. Yalom, (2002) also submitted that a congruent person is able to intentionally and verbally reveal personal feelings, thoughts, impressions, experiences, facts, views, values, and methods of working. Besides, congruence has been described as an inner attitude, a relational 
experience, and a dynamic process between client and therapist (Geller and Greenberg, 2002).

Furthermore, this study revealed that unconditional positive regard was significantly related to success potential of Catholic priests in selected Dioceses in the Southwest of Nigeria. The result of this study actually confirmed previous study conducted by Lietaer (2001) where unconditional positive regard thus produces a high level of safety which helps unfreeze blocked areas of experience in a therapeutic relationship. Likewise, Wilkins (2000) recognized a direct relationship between one's unconditional positive self-regard and one's ability to provide unconditional positive regard for a client. Unconditional positive regards help the counsellor accurately perceive and accept the counsellee as individual that is full of good sides, regardless of the maladaptive behaviour that the counsellee might have engaged in. Besides the professional characteristic of unconditional positive regard always focus on solution, rather than the presenting "problem".

Moreover, the result of this study on the relationship between emphatic understanding and success potential is in support of Ritter, Bowden, Murray, Ross, Greeley and Pead, (2002) who found that therapist empathy and expertness were associated with improvements in client drinking outcomes in multiple domains. Empathy is often viewed as important for treatment outcomes, yet as a construct it lacks consistency in definition and assessment (Elliott, Bohart, Watson and Greenberg, 2011; Gerdes, Segal and Lietz, 2010; Neukrug, Bayne, Dean-Nganga and Pusateri, 2013). In addition, Pantalon, Chawarski, Falcioni, Pakes and Schottenfeld (2004) discovered a significant relationship between more positive therapist skills (empathy) in managing resistance and improved cocaine abstinence of participants. Empathy enables an individual to be able to accurately understand and relate with the issue that counsellee is presenting; and in such a situation, the counsellor is more likely to achieve more success than when empathy is lacking.

Moreover, this study established that reflective listening is significantly related to success potential of the priests in selected Dioceses in the Southwest of Nigeria. This study corroborate the result of the study conducted by Segre, Chuffo-Siewert, Brock and O'Hara (2013) where it was found that a significant improvement in quality of life of clients following therapeutic treatments is a function of reflective listening. In addition, Shakespeare, Blake and Garcia (2009); Turner, Chew-Graham, Folkes, Sharp (2010) also found that reflective listening skill is a significant pre-requisite for effective guidance and counselling program. One important reason for the significance of reflective listening indicates that the therapist should possess the capability to ensure that the content of the client's story is not altered but correctly interpreted. This step will make a client to see therapist as a partner and friend, who is willing to render help that could help overcome the pressing challenges.

The second research question examined the joint contribution of perceived professional characteristics (genuineness, unconditional positive regard, empathic understanding and reflective listening) to success potential of Catholic Priests in selected Diocese in the Southwest of Nigeria. The result obtained from this research question revealed that genuineness, unconditional positive regard, empathic understanding and reflective listening had significant joint contribution to success potential of Catholic Priests in selected Dioceses in the Southwest of Nigeria. This result is in support of past related studies, such as that of Lee and Prior (2013) where counsellor's professional characteristics were significant determinants of counselling effectiveness. In the same vein, Mineyama, Tsutsumi, Takao, Nishiuchi and Kawakami (2007) found that skills and attitudes for therapeutic listening is a determinant factor for reducing psychological stress. Mesquita and de Carvalho (2014) concluded that therapeutic characteristics of therapist are important skills to bring about effective counselling. When counsellor possess the appropriate professional characteristics it will help by providing conducive positive therapeutic conditions that can facilitate a successful therapeutic session, especially in the area of remedial and reformatory program.

The third research question investigated the relative contribution of perceived professional characteristics (genuineness, unconditional positive regard, empathic understanding and reflective listening) to success potential of Catholic Priests in selected Dioceses in the Southwest of Nigeria. The result of this study supported that each of the independent variables (genuineness, unconditional positive regard, empathic understanding and reflective listening) had significant contribution to success potential of Catholic Priests in selected Dioceses in the Southwest of Nigeria. The result of this study support previous study where genuineness has been found to be a significant determinant of counselling effectiveness (Grafanaki, 2001; Schnellbacher, 2005). The significant determination of success potential by genuineness could that explain a therapist that is genuine is able to have helpful assessment of strength and weakness of both the therapist and the client; and this helps facilitate effective therapeutic relationship between therapist and client.

In addition, this study demonstrates that unconditional positive regard significantly determined success potential of the participants. This result supports previous research results conducted by Cochran, Cochran and Sherer (2012) where it was discovered that unconditional positive regard influence the apparent counselling progress and contribute to therapist's growth and development. Similarly, Farber and Doolin (2011) concluded that the therapist's ability to provide positive regard is significantly associated with therapeutic success.

In similar vein, previous studies (e.g. Fiorentine and Hillhouse, 1999) have found that clients' ratings of their counselor's empathy were significantly correlated with both treatment engagement and abstinence rates. Moyers 
and Miller (2014) found that "pre-employment screening" empathy ratings were a significant predictor of clinician empathy in later therapy sessions and effectiveness. In addition, Pearson (2007) found that counsellor's effectiveness has a lot to do with emphaty. Cook, Juhnke, Peters, Marbach, Day, Choucroun and Baker (2007) found that expressing emphatic understanding often make the clients feel connected to therapeutic session. A therapist that is capable of having accurate picture and understanding of the client's presenting issue, will go a long way to help the clients effectively develop means of resolving the issues or challenges.

Furthermore, this study confirmed that reflective listening significantly determined the success potential of priests especially those that engage in remedial and reformatory program. This result is in support of previous study carried out by Segre, Stasik, O'Hara and Arndt, (2010) where the result showed that therapeutic listening was significant counsellors factor that helped women with depressive symptoms. In addition, Sharp, ChewGraham, Tylee, Lewis, Howard, Anderson, et al. (2010) found that progress in counselling process and effectiveness depends on the listening skills of the counsellor. These findings could be substantiated by saying that reflective listening do help therapist to accurately understand what client is trying to relate in a therapeutic relationship.

\section{Conclusion}

This study investigated perceived professional characteristics as correlates of success potential of Catholic Priests in selected Dioceses in the Southwest of Nigeria. The professional characteristics used were genuineness, unconditional positive regard, empathic understanding and reflective listening. Data were collected from the respondents and the data were properly analyzed using Pearson Moment Correlation and Multiple Regression Analysis. Based on the result of this study, it could be concluded that each of the independent variables (genuineness, unconditional positive regard, empathic understanding and reflective listening) had significant contribution to success potential of Catholic Priests

\section{Recommendation}

Based on the conclusion of this study, the following recommendations were made:

- Catholic priests should be exposed to training programs that will help them imbibe helpful professional characteristics that could contribute positively to success potential

- In addition, Catholic priests should be given special training on genuineness, unconditional positive regard, empathic understanding and reflective listening as such will contribute significantly to success potential.

Moreover, in order to achieve success, the training curriculum of the Catholic priesthood should be made to include aspects of helpful professional characteristics, such as genuineness, unconditional positive regard, empathic understanding and reflective listening.

\section{References}

Akinade, E. A. 2012. Modern Behaviour modification, principles and practices. Ibadan: BrightWay Publishers.

Akinboye, J. O. 2003. Creativity, Innovation and Success, Ibadan, Stirling- Horden (Nig) Ltd.

American Psychiatric Association (APA). 2013. Diagnostic and statistical manual of mentaldisorders (5th ed.). Washington, DC: American Psychiatric Association.

Anderson T, Ogles B. M, Patterson, C. L, Lambert, M. J, Vermeersch, D. A. 2009. Therapist effects:Facilitative interpersonal skills as a predictor of therapist success. Journal of Clinical Psychology; 65(7): 755-768.

Animasahun R.A. 2007. Success Potential Battery (SPB)

Animasahun R. A. 2012. Leadership, An Extract From Lecture from Lecture on MPP 721 Individual and Group Behaviour in Organisation, Department of Guidance and Counselling, University of Ibadan.

Animasahun, R. A. 2013. Development and Validation of Success Potential. Global Journal of Human Science Arts and Humanities, vol 13, Issue 1, Version 1.0

Batson, C. D. 2011. These things called empathy: Eight related but distinct phenomena. In J. Decety, \& W. Ickes (Eds.), The social neuroscience of empathy (pp. 3-16). Cambridge, MA: MIT Press.

Besel, L. D. S., and Yuille, J. C. 2010. Individual differences in empathy: The role of facial expression recognition. Personality and Individual Differences, 49, 107-112. Cochran, J.L. Cochran N.H. and Sherer, L.C. 2012. Unconditional Positive Regard and Limits: A Case Study in Child-Centered Play Therapy and Therapist Development; The Person Centered Journal, 19(1-2), 3-28.

Chawarski, M. C, Falcioni, J., Pakes, J. and Schottenfeld, R. S. 2004. Linking process and outcome in the community reinforcement approach for treating cocaine dependence: A preliminary report. American Journal of Drug and Alcohol Abuse; 30(2):353-367.

Cook, K., Juhnke, G. A., Peters, S. W., Marbach, C. R., Day, S., Choucroun, P., and Baker, R. E. 2007. Promoting clinical knowledge, skills, and empathy via a creative self-suicideassignment: Rationale, purpose, and student responses. Journal of Creativity in Mental

Health, 2(2), 39-46. 
Ebizie, E. N., Enajedu, E. E. and Nkechi, E. 2016. The Role of Guidance and Counselling in Effective Teaching and Learning in Schools. RAY: International Journal of Multidisciplinary Studies, I(2), 36-48.

Egbo, A. C. 2013. Development of Guidance and counselling. Enugu: Joe best publishers.

Elliott, R., Bohart, A. C., Watson, J. C., and Greenberg, L. S. 2011. Empathy. In J. Norcross (ed.), Psychotherapy relationships that work (2nd ed.) (pp. 132-152). New York: Oxford University Press. (c) Oxford University Press.

Farber, B. A. and Lane, J. S. 2011. Positive regard. In J.C. Norcross (Ed), Psychotherapyrelationships that work. New York, NY: Oxford University Press.

Gerdes, K. E., Segal, E., and Lietz, C. 2010. Conceptualising and measuring empathy. British Journal of Social Work, 40(7), 2326-2343. https://doi.org/10.1093/bjsw/bcq048

Kohut, H. 2010. On Empathy, International Journal of Psychoanalytic Self Psychology, 5:2, 122-131.

Kolden, G. G., Klein, M. H., Wang, C. and Austin, S. B. 2011. Congruence/Genuineness. In J. C.Norcross (Ed.), Psychotherapy Relationships that Work: Evidence-Based Responsiveness (2nd ed.) (pp. 187-202). New York: Oxford University Press.

Lai-Yeung, S. W. C. 2014. The need for guidance and counselling training for teachers. Procedia-Social and Behavioral Sciences, 113, 36-43.

Lambert, M. J. 1992. Implications of outcome research for psychotherapy integration. In N. J. Norcross \& M.R. Goldfried (Eds.) Handbook of psychotherapy integration (pp. 94-129).New York: Basic Books.

Landreth, G. 2012. Play therapy: The art of the relationship. New York, NY: Routledge.

Lee B and Prior S. 2013. Developing therapeutic listening. Br J Guid Couns.;41(2):91-104.

Mineyama S, Tsutsumi, A, Takao, S, Nishiuchi, K. and Kawakami, N. 2007. Supervisors' attitudes and skills for active listening with regard to working conditions and psychological stressreactions among subordinate workers. J Occup Health.; 49(2):81-7.

Moyers, T. B. and Miller, R. M. 2013. Is Low Therapist Empathy Toxic? Psychol. Addict. Behav; (3): 878-884.

Neukrug, B., Dean-Nganga and Pusateri. 2013. Creative and Novel Approaches to Empathy: A Neo-Rogerian Perspective, Journal of Mental Health Counseling, 10.17744/mehc.35.1.5q375220327000t2, 35(1), 29-42

O'Hara, D. J., and O'Hara, E. F. 2015. Counselling and psychotherapy: Professionalisation in the Australian context. Psychotherapy and Counselling Journal of Australia (PACJA), 3 [online]. Retrieved from http://pacja.org.au/?p=2732

Oviogbodu, C. O. 2015. Perceived impact of guidance and counseling in the development of Niger Delta Region. Paper present at Niger Delta University conference with the theme: education and sustainable development in the Niger Delta region of Nigeria. Held at the University Entrepreneur Center new site Niger Delta University, Wilberforce island, Amasoma, Bayalsa State Nigeria from 9th - 12th August. Pantalon MV,

Patterson, T. and Joseph, S. 2007. Person-Centered Personality Theory: Support from Self-Determination Theory And Positive Psychology. Journal of Humanistic Psychology 47(1):117-139.

Pederson P. 2009. Inclusive Cultural Empathy: A Relationship-Centred Alternative to Individualism. https://doi.org/10.1177/008124630903900201

Preston, S. D. 2007. A perception-action model for empathy. In T. F. D. Farrow, \& P. W. R. Woodruff (Eds.), Empathy in mental illness (pp. 428-447). Cambridge: Cambridge University Press.

Psychotherapy and Counselling Federation of Australia, (PACFA) 2018. Scope of Practice for Registered Counsellor. Australia, Author

Rautalinko E, Lisper, H. O. and Ekehammar, B. 2007. Reflective listening in counseling: effects of training time and evaluator social skills. Am J Psychother.; 61(2):191-209.

Ray, D. C. 2011. Advanced play therapy: Essential conditions, knowledge, and skills for childpractice. New York, NY: Routledge.

Rogers, C. 1975. Empathic: An unappreciated way of being. The Counseling Psychologist, 5, 2-10. Schnellbacher, J., and Leijssen, M. 2009. The significance of therapist genuineness from the client's perspective. Journal of Humanistic Psychology, 49(207).

Segre L. S, Stasik S. M, O’Hara M. W, and Arndt S. 2010. Listening visits: an evaluation of the effectiveness and acceptability of a home-based depression treatment. Psychother Res.; 20(6):712-21.

Shakespeare J, Blake F. and Garcia J. 2006. How do women with postnatal depression experience listening visits in primary care? A qualitative interview study. J Reprod Infant Psychol.; 24(2):149-62.

Shariff, A. F., Willard, A. K., Andersen, T., and Norenzayan, A. 2016. Religious priming: A meta-analysis with a focus on prosociality. Personality and Social Psychology Review, 20, 27-48.

Theron, M. J. 2008. A Manual for Basic Relational Skills Training in Psychotherapy, Masters Thesis, University of South Africa.

Tolan, J. 2012. Skills in person-centered counselling and psychotherapy. Thousand Oaks, C A:Sage Publications. Wilkins, P. 2010. Person-centered therapy: 100 key points. London, England: Routledge.

Wosket, V. 2007. Egan's Skilled Helper Model: Developments and Applications in Counselling. London: 
Routledge.

Wyatt, G.2001. Rogers' therapeutic conditions: Evolution, theory and practice. Vol. 1 Congruence. Ross-on-Wye, England: PCCS Books.

Yunus, B., Mehmet, H and Onurcan, Y. 2018. The Relationship Between Attachment to God, Prosociality and Image of God. Archive for the Psychology of Religion 40, 202-224.

Zaki, J., Weber, J., Bolger, N., and Ochsner, K. 2009. The neural bases of empathic accuracy. PNAS, 106, 1138211387.

Zhu, J. 2017. Why self awareness matters and how to be more self-aware, in positive psychology.com 